\title{
Effect of reinforcement amount, mold temperature, superheat, and mold thickness on fluidity of in-situ $\mathrm{Al}-\mathrm{Mg}_{2} \mathrm{Si}$ composites
}

\author{
* Reza Vatankhah Barenji \\ Department of Industrial Engineering, Hacettepe University, Beytepe Campus, Ankara 06800, Turkey
}

\begin{abstract}
In the present study, the effects of mold temperature, superheat, mold thickness, and $\mathrm{Mg}_{2} \mathrm{Si}$ amount on the fluidity of the $\mathrm{Al}-\mathrm{Mg}_{2} \mathrm{Si}$ as-cast in-situ composites were investigated using the mathematical models. Composites with different amounts of $\mathrm{Mg}_{2} \mathrm{Si}$ were fabricated, and the fluidity and microstructure of each were then analyzed. For this purpose, the experiments were designed using a central composite rotatable design, and the relationship between parameters and fluidity were developed using the response surface method. In addition, optical and scanning electron microscopes were used for microstructural observation. The ANOVA shows that the mathematical models can predict the fluidity accurately. The results show that by increasing the mold temperature from $25^{\circ} \mathrm{C}$ to $200{ }^{\circ} \mathrm{C}$, superheat from $50{ }^{\circ} \mathrm{C}$ to $250{ }^{\circ} \mathrm{C}$, and thickness from $3 \mathrm{~mm}$ to $12 \mathrm{~mm}$, the fluidity of the composites decreases, where the mold thickness is more effective than other factors. In addition, the higher amounts of $\mathrm{Mg}_{2} \mathrm{Si}$ in the range from $15 \mathrm{wt} . \%$ to $25 \mathrm{wt} . \%$ lead to the lower fluidity of the composites. For example, when the mold temperature, superheat, and thickness are respectively $100{ }^{\circ} \mathrm{C}, 150{ }^{\circ} \mathrm{C}$, and $7 \mathrm{~mm}$, the fluidity length is changed in the range of $11.9 \mathrm{~cm}$ to $15.3 \mathrm{~cm}$. By increasing the amount of $\mathrm{Mg}_{2} \mathrm{Si}$, the morphology of the primary $\mathrm{Mg}_{2} \mathrm{Si}$ becomes irregular and the size of primary $\mathrm{Mg}_{2} \mathrm{Si}$ is increased. Moreover, the change of solidification mode from skin to pasty mode is the most noticeable microstructural effect on the fluidity.
\end{abstract}

Key words: Al- $\mathrm{Mg}_{2} \mathrm{Si}$; composites; microstructure; fluidity
CLC numbers: TG146.2
Document code: $\mathrm{A}$
Article ID: 1672-6421(2018)01-066-09

\begin{abstract}
A luminum matrix composites (AMCs) are frequently used in different industries. This is due to the fact that AMCs are light and have good specific strength and stiffness. Thus, these new materials can be an appropriate option for replacement of the heavy alloys such as steels ${ }^{[1-8]}$.

AMCs can be produced using casting methods such as ex-situ and in-situ processes. In the ex-situ process, reinforcement particles are added to the molten metal, usually accompanied by a stirring action. In the insitu process, the reinforcements of secondary phase are produced either in molten metal or in solidification. Therefore, the wetting problem of the secondary phases is solved by the in-situ method, and hence the distribution of the reinforcements is more uniform than that of the ex-situ method. This advantage of the in-situ
\end{abstract}

${ }^{*}$ Reza Vatankhah Barenji

Male, Ph.D., Senior Lecturer. His research interests include: friction stir welding, friction stir processing, response surface methodology, digital manufacturing, CAD/CAM, manufacturing control systems, manufacturing knowledge modeling, etc.

E-mail:Reza.vatankhah@hacettepe.edu.tr

Received: 2017-07-03; Accepted: 2017-10-14 processes have made AMCs more suitable for some industrial applications ${ }^{[9-12]}$.

One of the suitable reinforcements for the AMCs is $\mathrm{Mg}_{2} \mathrm{Si}$ because it is light, and has a high melting point and elastic modulus ${ }^{[13]}$. According to the $\mathrm{Al}-\mathrm{Mg}_{2} \mathrm{Si}$ phase diagram, $\mathrm{Mg}_{2} \mathrm{Si}$ reinforcements can be produced from molten $\mathrm{Al}$ during solidification as follows ${ }^{[14]}$ :

$\mathrm{L} \rightarrow\left(\mathrm{Mg}_{2} \mathrm{Si}\right)_{\mathrm{P}}+\mathrm{L}_{1} \rightarrow\left(\mathrm{Mg}_{2} \mathrm{Si}\right)_{\mathrm{P}}+\left(\left(\mathrm{Mg}_{2} \mathrm{Si}\right)_{\mathrm{S}}+\mathrm{Al}_{\alpha}\right)_{\mathrm{E}}$

where, E is eutectic, P refers to primary, S stands for secondary, and $\mathrm{L}_{1}$ belongs to liquid in the two-phase region.

On casting of alloys and MMCs, one of the most important parameters that should be controlled to produce sound castings is the fluidity ${ }^{[15]}$, which is described as the ability of molten metal to fill a mold at a particular temperature before solidification. In general, the fluidity of metals and alloys is affected by many parameters which can be categorized as follows: (a) metallurgical factors including composition, superheat, solidification mode, latent heat, surface tension, viscosity, and the presence of surface oxides and (b) mold/casting factors including mold temperature, mold 
conductivity, and the heat transfer coefficient at the interface. For controlling the fluidity, in the first step, the effective parameters should be distinguished and then controlled ${ }^{[16]}$. In this regard, some researchers have studied the influence of casting parameters on the fluidity of $\mathrm{Al}$ and its alloys ${ }^{[15-18]}$. Moreover, some researchers have investigated the fluidity of the AMCs ${ }^{[19,21]}$. For example, Heidarzadeh et al. ${ }^{[21]}$ added $\mathrm{Cu}$ to the $\mathrm{Al}-$ $15 \mathrm{wt} . \% \mathrm{Mg}_{2} \mathrm{Si}$, and investigated its effect on the fluidity using a multi-channel mold. Their results showed that the $\mathrm{Cu}$ causes a wider solidification interval, which leads to higher viscosity and lower fluidity. In comparison with alloys, the fluidity of the AMCs is affected by some other factors in addition to the above mentioned factors. These factors include the volume fraction of the reinforcing particles, and the size and shape of the particles. In the case of particle dispersed composites, the fluidity at any given temperature is decreased relative to the particle free base alloy ${ }^{[22-24]}$. Some authors ${ }^{[25,26]}$ have shown this decreases with a decrease in the reinforcement particle size for a given volume fraction of particles. The morphology of the reinforcement influences the fluidity of composite melts because of its effect on the surface area to volume ratio of the dispersed phase. Increasing angularity of the reinforcing particles leads to a progressively greater decrease in the fluidity at a given temperature and volume fraction of the particle ${ }^{[25]}$.

Although some investigators have studied the fluidity of the AMCs, an examination into the influence of casting parameters on the fluidity of the Al- $\mathrm{Mg}_{2} \mathrm{Si}$ in-situ composites has not been studied until now. Consequently, in this study, the effects of $\mathrm{Mg}_{2} \mathrm{Si}$ content, mold temperature, superheat, and channel thickness on the fluidity and microstructure of the $\mathrm{Al}-\mathrm{Mg}_{2} \mathrm{Si}$ composites have been explored. For this purpose, central composite rotatable design (CCRD), in conjunction with response surface method (RSM) was used to design the experiments.

\section{Materials and methods}

\subsection{Experimental procedures}

\subsubsection{Ingot preparation}

The base materials used in this investigation were Al15 wt. $\% \mathrm{Mg}_{2} \mathrm{Si}, \mathrm{Al}-17.5$ wt. $\% \mathrm{Mg}_{2} \mathrm{Si}, \mathrm{Al}-20$ wt. $\% \mathrm{Mg}_{2} \mathrm{Si}, \mathrm{Al}-$ $22.5 \mathrm{wt} . \% \mathrm{Mg}_{2} \mathrm{Si}$ and $\mathrm{Al}-25 \mathrm{wt} . \% \mathrm{Mg}_{2} \mathrm{Si}$ composites. Industrially

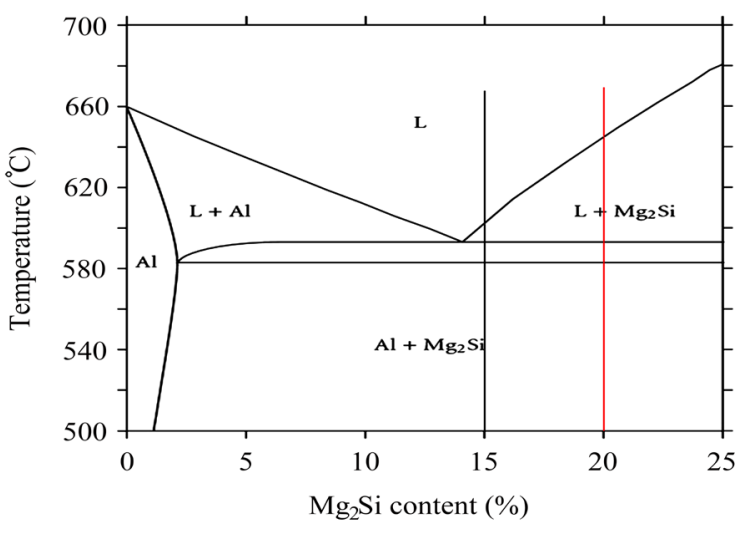

Fig. 1: Equilibrium binary phase diagram of $\mathrm{Al}-\mathrm{Mg}_{2} \mathrm{Si}$

pure $\mathrm{Al}(99.8 \%), \mathrm{Mg}(99.9 \%)$ and $\mathrm{Si}(99.2 \%)$ metals were utilized for preparing the composite ingots with $15 \mathrm{wt} . \%-25 \mathrm{wt} . \% \mathrm{Mg}_{2} \mathrm{Si}$. Melting was conducted in an electrical resistant furnace with a controlled atmosphere and temperature $\left( \pm 5^{\circ} \mathrm{C}\right.$ accuracy). After reaching $800{ }^{\circ} \mathrm{C}$ in a $\mathrm{SiC}$ crucible with $10 \mathrm{~kg}$ capacity via the electrical resistance furnace, $\mathrm{Si}$ and $\mathrm{Mg}$ were added into the $\mathrm{Al}$ melt (to account for losses, an extra 20wt.\% Mg and 7wt.\% Si were added above the stoichiometric requirements). In addition, the atmosphere of the furnace was controlled using Argon gas. Table 1 shows the actual composition of the prepared composites.

\subsubsection{Microstructural characterization}

The specimens for microstructural study were cut from the same position of each ingot and examined by an Olympus 100 light microscope and a JEOL JSM 6500F field emission scanning electron microscope (SEM). For the purpose of this experiment, sections were cut through the composite ingots and were coldmounted, ground, polished, and etched with Keller's reagent (150 $\mathrm{ml}$ water, $3 \mathrm{ml}$ nitric acid, $6 \mathrm{ml}$ hydrochloric acid, $6 \mathrm{ml}$ hydrofluoric acid) at room temperature for OM and SEM. The $\mathrm{OM}$ and SEM were used to identify the $\mathrm{Mg}_{2} \mathrm{Si}$ content and morphology in the microstructure of the different composites.

\subsubsection{Fluidity test}

The fluidity tests were conducted on the AMCs with different amounts of $\mathrm{Mg}_{2} \mathrm{Si}$ using a multi-channel permanent mold. In this study, the spiral and vacuum fluidity tests were not selected. The spiral test has a constant cross section, and hence the results of this test cannot be used for castings with different thicknesses. On the other hand, the vacuum test is usually used in laboratory

Table 1: Chemical composition of different composites (wt.\%)

\begin{tabular}{lcccccccccccc}
\multicolumn{1}{c}{ Material } & $\mathrm{Si}$ & $\mathrm{Fe}$ & $\mathrm{Cu}$ & $\mathrm{Mn}$ & $\mathrm{Mg}$ & $\mathrm{Cr}$ & $\mathrm{Ni}$ & $\mathrm{Zn}$ & $\mathrm{Al}$ \\
\hline 15wt.\% $\mathrm{Mg}_{2} \mathrm{Si}$ & 5.72 & 0.16 & 0.01 & 0.01 & 9.82 & 0.01 & 0.01 & 0.12 & Base \\
17.5wt.\% $\mathrm{Mg}_{2} \mathrm{Si}$ & 6.68 & 0.14 & 0.01 & 0.01 & 11.22 & 0.02 & 0.02 & 0.08 & Base \\
20wt.\% $\mathrm{Mg}_{2} \mathrm{Si}$ & 7.70 & 0.12 & 0.01 & 0.01 & 12.80 & 0.02 & 0.02 & 0.11 & Base \\
22.5wt.\% Mg $2 \mathrm{Si}$ & 8.38 & 0.13 & 0.01 & 0.01 & 14.42 & 0.01 & 0.01 & 0.13 & Base \\
25wt.\% $\mathrm{Mg}_{2} \mathrm{Si}$ & 9.23 & 0.13 & 0.01 & 0.01 & 16.11 & 0.01 & 0.01 & 0.09 & Base
\end{tabular}


scales. Thus, the multi-channel test was selected for measuring the fluidity at different thicknesses. Figure 2 shows the multichannel test design, including six strips, pouring basin and running system. Each strip is $20 \mathrm{~mm}$ wide and $250 \mathrm{~mm}$ long. The thicknesses of the strips were: $1,3,5,7,9$ and $12 \mathrm{~mm}$. The mold internal surface was fully covered by Dycote 36 (FOSECO) using a spray gun. From our previous experimental results ${ }^{[21]}$, the mold and superheat temperatures were holding constant at $100{ }^{\circ} \mathrm{C}$ and $150^{\circ} \mathrm{C}$, respectively. In order to preheat the mold, it was placed on a heater and its temperature was controlled by a calibrated thermocouple placed into the center part of the drag. For this purpose, the molten AMCs was first prepared in an electric resistance furnace. Before pouring the molten AMCs into the mold, the oxide layers and dross were removed

(a)

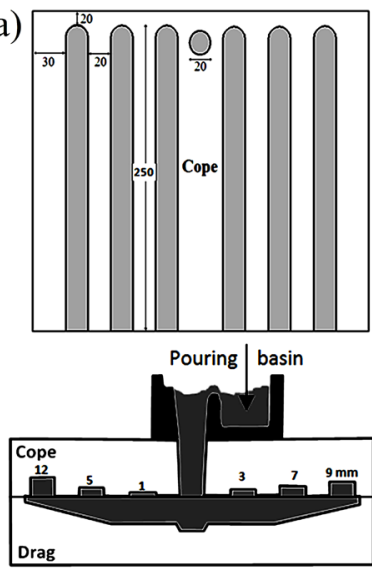

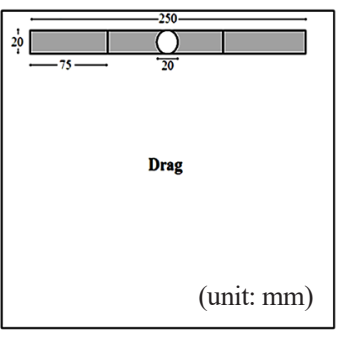

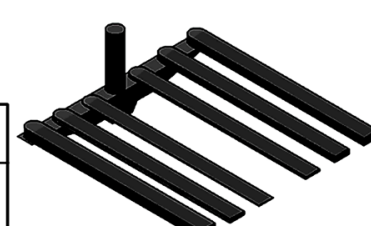

by skimming from the surface and the temperature of the molten metal was then measured by a fine and accurate K-type thermocouple. It is notable that the fluidity tests for each of the AMCs were repeated six times to obtain results that are more accurate. For this purpose, six results were taken to calculate the average amount of the fluidity.

\subsection{Design of experiments}

Typical experiment design methods such as full factorial, partial factorial and central composite rotatable designs (CCRD) are usually employed for process modeling. CCRD requires far fewer experiments than the full and partial factorial design. Hence, in this study, due to a wide range of parameters, CCRD consisting of 31 sets of runs, four selected independent parameters (mold

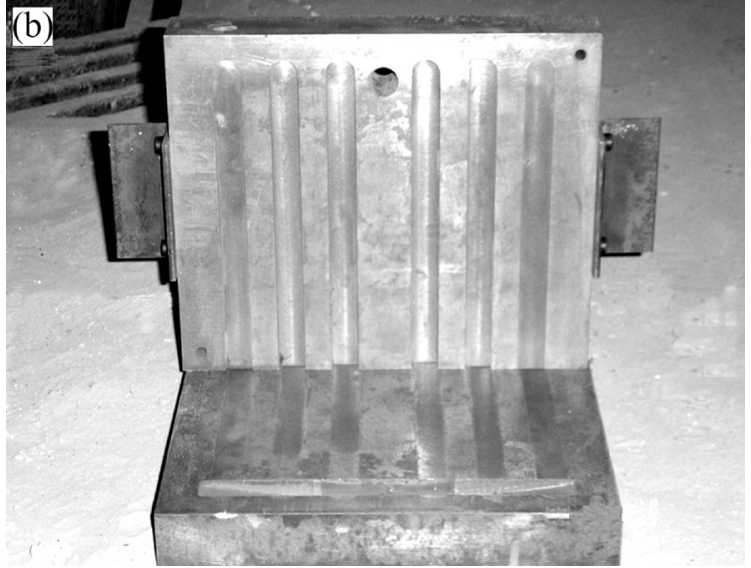

Fig. 2: (a) Schematics of fluidity test mold, and (b) image of corresponding mold

temperature, superheat, mold thickness, and $\mathrm{Mg}_{2} \mathrm{Si}$ amount) and five levels $( \pm \beta, \pm 1,0)$ were used to design the experiments, where $\beta=2 k / 4$ and $k$ is the number of independent parameters ${ }^{[27,28]}$. The processing parameter values and their levels involved in this investigation are summarized in Table 2. The measured response parameter was the fluidity length. The experiment design was created using the Design-Expert Version 8.0 software as presented in Table 3. Random experiments were done in order to avoid any systematic error entering into the system.

\subsection{Modeling}

In the present investigation, a second order polynomial regression model that includes the main and interaction effects of all parameters was developed to establish a mathematical relationship between the parameters and the fluidity of the composites. The response of fluidity is a function of mold temperature $(A)$, superheat $(B)$, thickness $(C)$, and $\mathrm{Mg}_{2}$ Si content $(D)$. The response surface can be expressed as follows:

$$
Y=f(A, B, C, D)
$$

The second order polynomial regression equation used in this study is given by ${ }^{[29-32]}$ :

$$
Y=b_{0}+\sum_{i=1}^{k} b_{i} k_{i}+\sum_{i=1}^{k} b_{i i} X_{i}^{2}+\sum_{i<j} b_{i j} X_{i} X_{j}
$$

where $Y$ is the response, $X_{i}$ and $X_{j}$ are the coded independent variables, $b_{0}$ is the mean values of responses and $b_{i}, b_{i i}$ and $b_{i j}$ are linear, quadratic and interaction constant coefficients,

\begin{tabular}{|c|c|c|c|c|c|c|}
\hline \multicolumn{5}{|c|}{ Levels } & \multirow{2}{*}{ Unit } & \multirow{2}{*}{ Parameters } \\
\hline$(+2)$ & $(+1)$ & (0) & $(-1)$ & $(-2)$ & & \\
\hline 200 & 150 & 100 & 50 & 25 & ${ }^{\circ} \mathrm{C}$ & Mold temperature $(A)$ \\
\hline 250 & 200 & 150 & 100 & 50 & ${ }^{\circ} \mathrm{C}$ & Superheat $(B)$ \\
\hline 12 & 9 & 7 & 5 & 3 & $\mathrm{~mm}$ & Channel thickness $(C)$ \\
\hline 25 & 22.5 & 20 & 17.5 & 15 & wt. $\%$ & $\mathrm{Mg}_{2} \mathrm{Si}$ amount $(D)$ \\
\hline
\end{tabular}

Table 2: Coded and actual values of parameters considered for design 
correspondingly. The values of the coefficients could be calculated by means of the following terms ${ }^{[29-32]}$.

$$
\begin{aligned}
& b_{0}=0.142857\left(\sum Y\right)-0.035714 \sum \sum\left(X_{i i} Y\right) \\
& b_{i}=0.041667\left(\sum X_{i} Y\right) \\
& b_{i i}=0.03125 \sum\left(X_{i i} Y\right)+0.00372 \sum \sum\left(X_{i i} Y\right)-0.035714\left(\sum Y\right) \\
& b_{i j}=0.0625 \sum\left(X_{i j} Y\right)
\end{aligned}
$$

For four parameters, the selected polynomials can be expressed as:

$U T S=b_{0}+b_{1}(A)+b_{2}(B)+b_{3}(C)+b_{4}(D)+b_{11}\left(A^{2}\right)+b_{22}\left(B^{2}\right)+b_{33}\left(C^{2}\right)+b_{44}\left(D^{2}\right)+$ $b_{12}(A B)+b_{13}(A C)+b_{14}(A D)+b_{23}(B C)+b_{24}(B D)+b_{34}(C D)$

By using the Design-Expert Version 0.8 software at 95\% confidence level, the regression coefficients of the second order polynomial regression model were calculated from the experiment data shown in Table 3. Furthermore, in order to ensure an accurate model, ANOVA analysis was performed including tests for significance of the regression model and coefficients. The model was presented as two dimensional plots (contour plots) using the same software.

\section{Results and discussion}

\subsection{ANOVA analysis and fitting of regression model}

The ANOVA results are shown in Table 4. From the F-value and P-value, the significance of the model and the coefficients can be indicated. For the more significant model and coefficients, larger F-value and smaller P-value are needed. The data of Table 4 show that the F-value and P-value of the model are 7.25 and 0.0001 , respectively, which demonstrate that the model is significant. The P-values smaller than 0.05 and greater than 0.1 indicate significant and not significant coefficients, correspondingly. According to the P-values, mold temperature $(A)$, superheat $(B)$, channel thickness $(C)$, and $\mathrm{Mg}_{2} \mathrm{Si}$ content $(D)$ are significant. Furthermore, all of the quadratic effects of parameters are not significant. Noting the F-values, the order of significant parameters will be as follows: $C>B>A>D$. The $R^{2}$ is calculated as 0.9214 , which indicate the adequacy of the developed model.

\begin{tabular}{|c|c|c|c|c|c|c|c|c|}
\hline \multirow{2}{*}{$\begin{array}{l}\text { Standard } \\
\text { run no. }\end{array}$} & \multirow{2}{*}{ Run } & \multicolumn{4}{|c|}{ Coded values of parameters } & \multicolumn{3}{|c|}{ Fluidity (cm) } \\
\hline & & $A$ & $B$ & C & $D$ & Experimental & Predicted & Error \% \\
\hline 1 & 18 & -1 & -1 & -1 & -1 & 7.9 & 7.16 & -9.4 \\
\hline 2 & 29 & 1 & -1 & -1 & -1 & 13.5 & 12.26 & -9.2 \\
\hline 3 & 26 & -1 & 1 & -1 & -1 & 14.3 & 13.06 & -8.7 \\
\hline 4 & 7 & 1 & 1 & -1 & -1 & 19.2 & 18.06 & -5.9 \\
\hline 5 & 2 & -1 & -1 & 1 & -1 & 17.5 & 16.01 & -8.5 \\
\hline 6 & 20 & 1 & -1 & 1 & -1 & 16.5 & 16.51 & 0.1 \\
\hline 7 & 5 & -1 & 1 & 1 & -1 & 17.9 & 19.26 & 7.6 \\
\hline 8 & 17 & 1 & 1 & 1 & -1 & 21 & 21.96 & 4.6 \\
\hline 9 & 21 & -1 & -1 & -1 & 1 & 3.8 & 3.46 & -8.9 \\
\hline 10 & 28 & 1 & -1 & -1 & 1 & 11.7 & 10.96 & -6.3 \\
\hline 11 & 8 & -1 & 1 & -1 & 1 & 8.1 & 7.51 & -7.3 \\
\hline 12 & 24 & 1 & 1 & -1 & 1 & 13.4 & 14.41 & 7.5 \\
\hline 13 & 16 & -1 & -1 & 1 & 1 & 10.1 & 10.36 & 2.6 \\
\hline 14 & 19 & 1 & -1 & 1 & 1 & 16.4 & 15.26 & -7 \\
\hline 15 & 22 & -1 & 1 & 1 & 1 & 17.2 & 16.06 & -6.6 \\
\hline 16 & 23 & 1 & 1 & 1 & 1 & 21 & 20.86 & -0.7 \\
\hline 17 & 30 & -2 & 0 & 0 & 0 & 7.6 & 8.13 & 7 \\
\hline 18 & 6 & 2 & 0 & 0 & 0 & 20.1 & 20.43 & 1.6 \\
\hline 19 & 1 & 0 & -2 & 0 & 0 & 3.8 & 4.08 & 7.4 \\
\hline 20 & 15 & 0 & 2 & 0 & 0 & 21 & 19.48 & -7.2 \\
\hline 21 & 11 & 0 & 0 & -2 & 0 & 1.3 & 1.42 & 9.2 \\
\hline 22 & 3 & 0 & 0 & 2 & 0 & 17.4 & 17.38 & -0.1 \\
\hline 23 & 10 & 0 & 0 & 0 & -2 & 16.6 & 17.68 & 6.5 \\
\hline 24 & 13 & 0 & 0 & 0 & 2 & 8.7 & 9.28 & 6.7 \\
\hline 25 & 27 & 0 & 0 & 0 & 0 & 13.2 & 13.35 & 1.1 \\
\hline 26 & 12 & 0 & 0 & 0 & 0 & 12.7 & 13.35 & 5.1 \\
\hline 27 & 9 & 0 & 0 & 0 & 0 & 14.4 & 13.35 & -7.3 \\
\hline 28 & 4 & 0 & 0 & 0 & 0 & 13.6 & 13.35 & -1.8 \\
\hline 29 & 14 & 0 & 0 & 0 & 0 & 14.1 & 13.35 & -5.3 \\
\hline 30 & 25 & 0 & 0 & 0 & 0 & 12.7 & 13.35 & 5.1 \\
\hline 31 & 31 & 0 & 0 & 0 & 0 & 13.3 & 13.35 & 0.4 \\
\hline
\end{tabular}
Also, from the error percentage shown in Table 3, it is obvious that the developed model can predict the fluidity within $\pm 10 \%$

Table 3: Design layout using Design-Expert Version 8.0 software including experimental and predicted results 
Table 4: ANOVA table for response surface model (response: Fluidity)

\begin{tabular}{|c|c|c|c|c|c|}
\hline Source & $\begin{array}{l}\text { Sum of } \\
\text { square }\end{array}$ & $\begin{array}{l}\text { Degree of } \\
\text { freedom }\end{array}$ & $\begin{array}{l}\text { Mean } \\
\text { square }\end{array}$ & F-value & P-value \\
\hline Model & 699.49 & 14 & 49.96 & 7.25 & 0.0001 \\
\hline$A$ & 147.01 & 1 & 147.01 & 21.35 & 0.0003 \\
\hline$B$ & 198.37 & 1 & 198.37 & 28.81 & $<0.0001$ \\
\hline$C$ & 245.76 & 1 & 245.76 & 35.70 & $<0.0001$ \\
\hline$D$ & 69.36 & 1 & 69.36 & 10.07 & 0.01 \\
\hline$A B$ & 0.01 & 1 & 0.01 & 0.01 & 0.97 \\
\hline$A C$ & 6.76 & 1 & 6.76 & 0.98 & 0.33 \\
\hline$A D$ & 5.76 & 1 & 5.76 & 0.83 & 0.37 \\
\hline$B C$ & 0.12 & 1 & 0.12 & 0.02 & 0.89 \\
\hline$B D$ & 0.02 & 1 & 0.02 & 0.01 & 0.95 \\
\hline$C D$ & 4.20 & 1 & 4.20 & 0.61 & 0.44 \\
\hline$A^{2}$ & 7.80 & 1 & 7.80 & 1.13 & 0.30 \\
\hline$B^{2}$ & 0.25 & 1 & 0.25 & 0.03 & 0.85 \\
\hline$c^{2}$ & 9.60 & 1 & 9.60 & 1.39 & 0.25 \\
\hline$D^{2}$ & 1.49 & 1 & 1.49 & 0.21 & 0.64 \\
\hline Residual & 103.25 & 15 & 6.88 & & \\
\hline$R^{2}$ & 0.9214 & & & & \\
\hline
\end{tabular}

their experiment values. The mathematical model in terms of coded parameters was obtained by multiple regression analysis on the experiment data as follows:

$$
\begin{aligned}
\text { Fluidity }(\mathrm{cm})= & 13.35+2.47 A+2.87 B+3.20 C-1.70 D-0.025 \mathrm{AB} \\
& -0.65 A C+0.60 A D 0.087 B C+0.038 B D+0.51 C D \\
& +0.53 A^{2}+0.096 B^{2}-0.59 C^{2}+0.23 D^{2}
\end{aligned}
$$

Equation (9) can be used to predict the fluidity within the range process parameters. By eliminating the non-significant terms of the developed equation, the reduced model is reached as follows:

$$
\text { Fluidity }(\mathrm{cm})=13.35+2.47 A+2.87 B+3.20 C-1.70 D
$$

Equation (10) shows the final relationship between fluidity and process parameters. The normal probability plot of the residuals, and the predicted response versus actual values for the response fluidity are illustrated in Figs. 3 and 4. In a normal probability plot (also called a "normal plot"), the sorted data are plotted vs. values selected to make the resulting image look close to a straight line if the data are approximately normally distributed. Deviations from a straight line suggest departures from normality. According to Fig. 3, it is obvious that errors are spread normally because the residuals fall on a straight line. In plotting the predicted response versus actual values, the predicted values are considered for the vertical axis of the plot, and the actual values are considered for the horizontal axis. If the data of this plot are embedded on a line with a slope of $45^{\circ}$, the model predicts accurately. Figure 4 reveals that the predicted response values are in good agreement with the actual ones within the ranges of the process parameters. Comparing the current results with the results of other investigators shows that similar plots should be achieved for developing accurate models. For instance, Barenji et al. ${ }^{[27]}$ for electrical discharge machining of the AISI D6 tool steel, Rajakumar et al. ${ }^{[31]}$ and Heidarzadeh et al. ${ }^{[33]}$ for friction stir welding of the alloys have used RSM, and have achieved similar plots for their developed models and experimental design matrix.

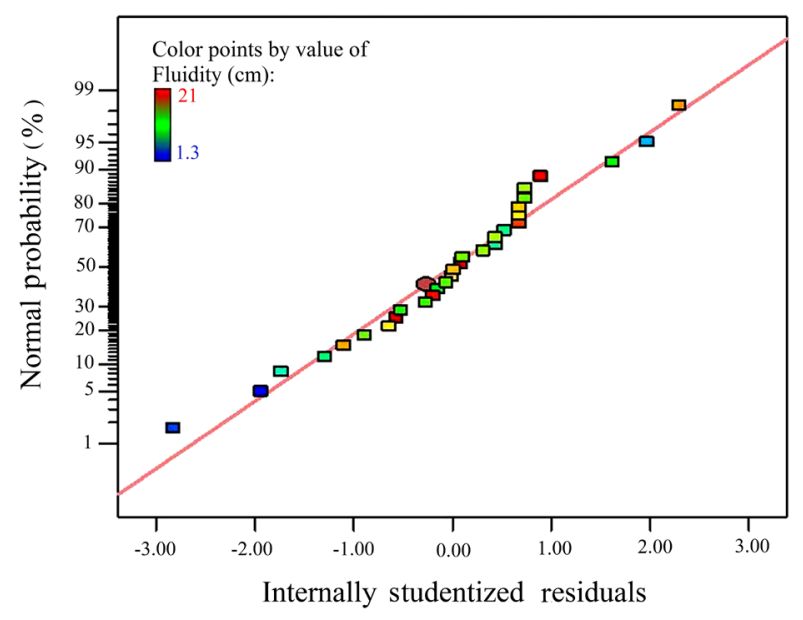

Fig. 3: Normal probability plot of residuals for fluidity

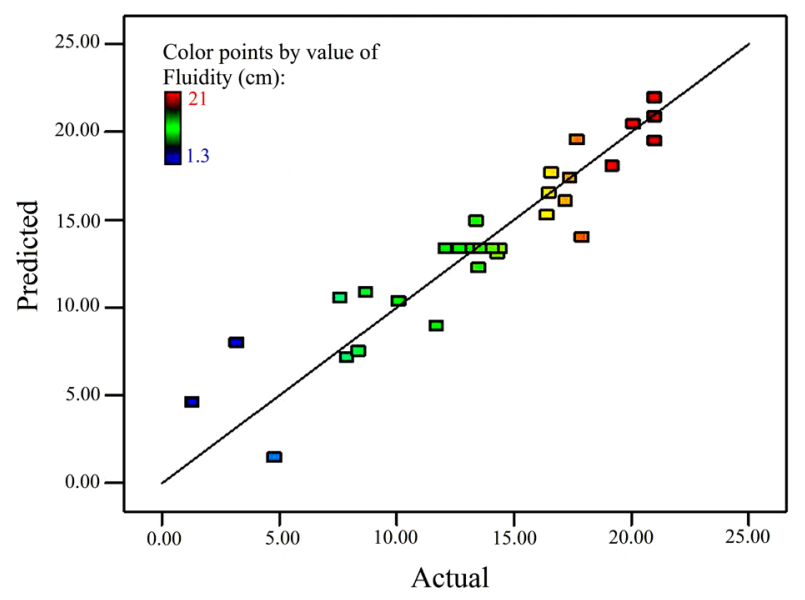

Fig. 4: Plot of predicted response versus actual value for fluidity

\subsection{Effect of parameters on Fluidity}

Figure 5 shows the perturbation plot of fluidity, which indicates that the order of effective parameters is as follows: $C>B>A>D$. In addition, Figure 6 depicts the contour plots. From Figs. 5 and 6 , in all of the channels, the fluidity increases with increasing superheat. Higher pouring temperature or larger melt superheat postpones the formation and growth of the solidified particles at the front of the molten metal, which leads to longer fluidity 
length. The other result from Figs. 5 and 6 is the fact that the fluidity length rises quickly with an increase in mold temperature up to $200{ }^{\circ} \mathrm{C}$, which is due to the lower chilling effect of the hot mold. Moreover, according to the counter plots and the ANOVA results in Table 4, the interaction between the casting parameters is negligible. This is due to low F-value and high P-value for the $A B, A C, A D, B C, B D$, and $C D$ coefficients. This means that the $A, B, C$, and $D$ parameters influence the fluidity length of the composite, independently.

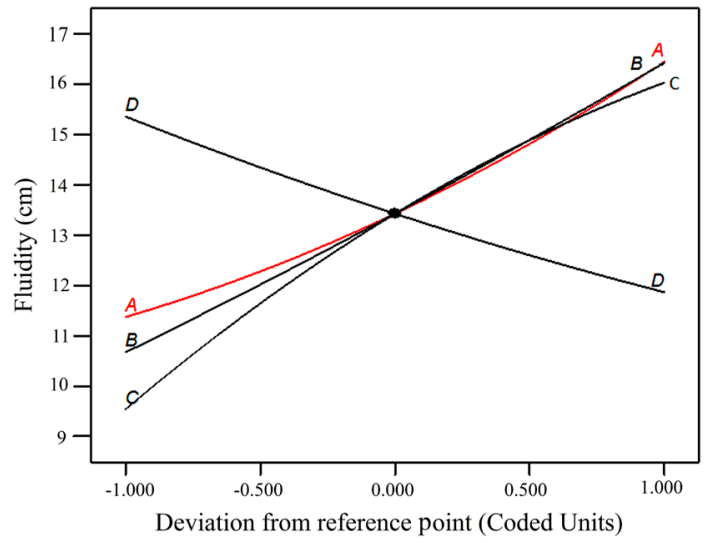

Fig. 5: Perturbation plot showing effect of all parameters on fluidity
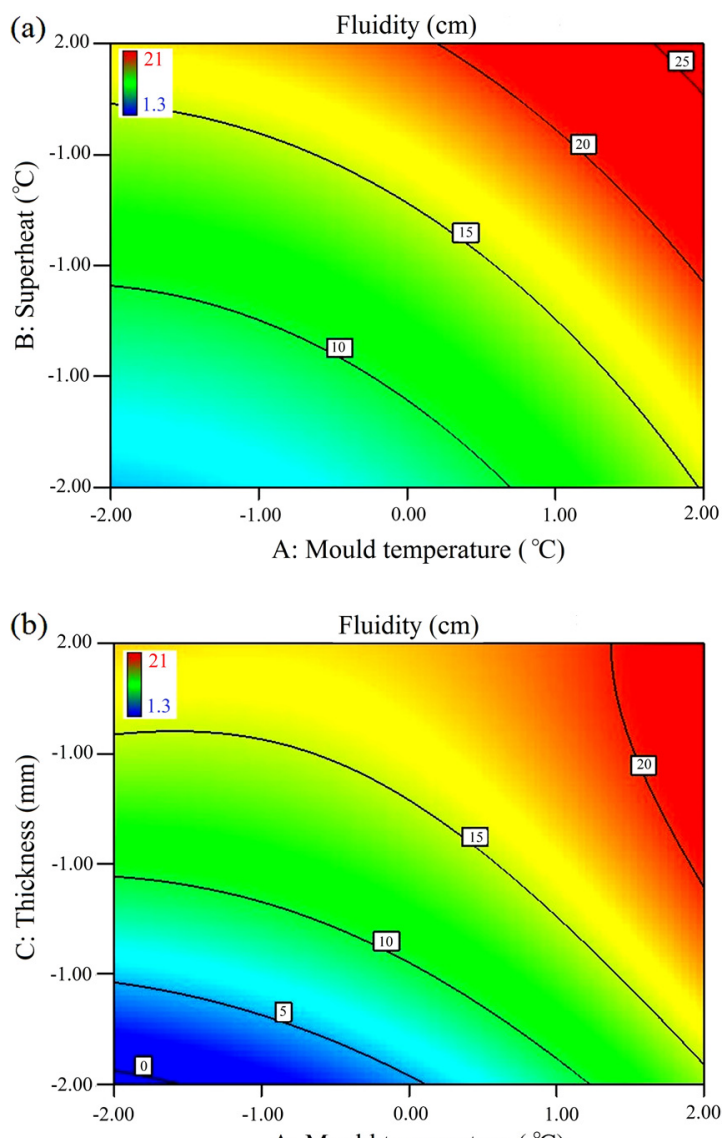

A: Mould temperature $\left({ }^{\circ} \mathrm{C}\right)$
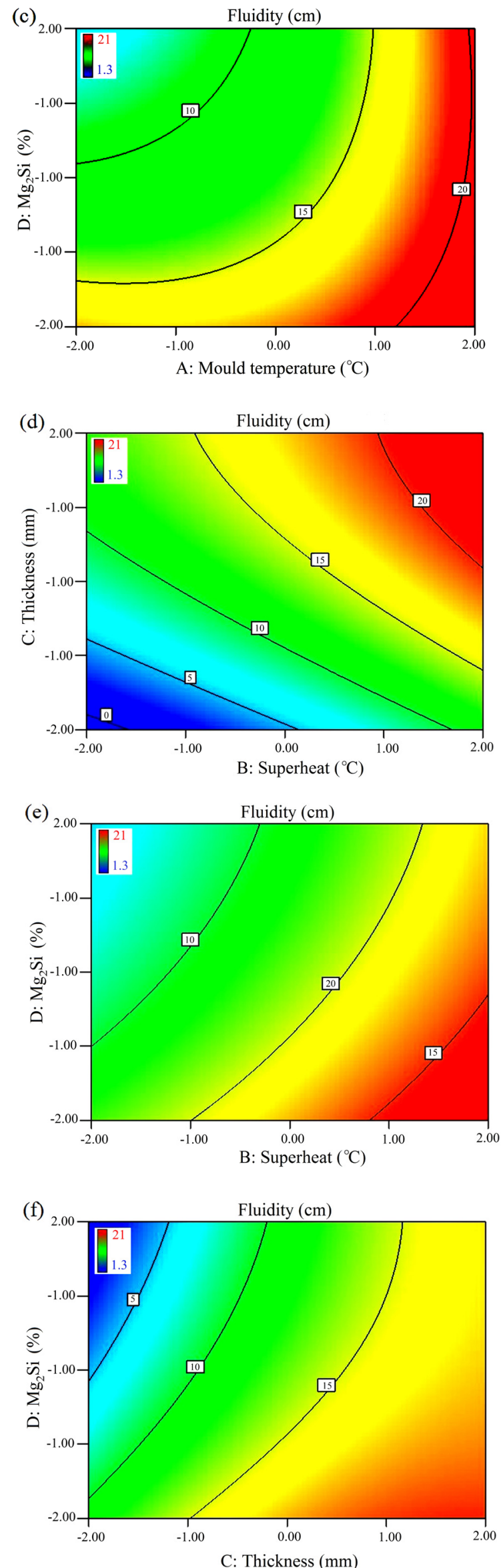

Fig. 6: Contour plots showing interaction effect of: (a) mold temperature and superheat, (b) mold temperature and mold thickness, (c) mold temperature and $\mathrm{Mg}_{2} \mathrm{Si}$ content, (d) superheat and mold thickness, (e) superheat and $\mathrm{Mg}_{2} \mathrm{Si}$ content, and (f) mold thickness and $\mathrm{Mg}_{2} \mathrm{Si}$ content 
From Figs. 5 and 6 showing the effect of $\mathrm{Mg}_{2} \mathrm{Si}$ content on the fluidity, it is clear that with increasing the $\mathrm{Mg}_{2} \mathrm{Si}$ content, a significant decrease in the fluidity has occurred in the case of all the channels. This result can be explained according to both the microstructure and phase diagrams. According to the microstructures shown in Figs. 7 and 8, some major outcomes can be obtained. First, the primary $\mathrm{Mg}_{2} \mathrm{Si}$ are faceted with some white points ${ }^{[12]}$, as shown in Fig. 8. These areas with white color inside the $\mathrm{Mg}_{2} \mathrm{Si}$ particles are pure $\alpha-\mathrm{Al}$. Second, the $\alpha-\mathrm{Al}$ is also found in the regions surrounding the primary $\mathrm{Mg}_{2} \mathrm{Si}$ particles, which can be because of the non-equilibrium solidification ${ }^{[15]}$. Third, with increasing the amount of $\mathrm{Mg}_{2} \mathrm{Si}$ phase, the primary $\mathrm{Mg}_{2} \mathrm{Si}$ amount seems to be increased. In addition, at a higher amount of $\mathrm{Mg}_{2} \mathrm{Si}$ phase, the morphology of the primary $\mathrm{Mg}_{2} \mathrm{Si}$ changes from faceted to irregular and dendritic, and the eutectic
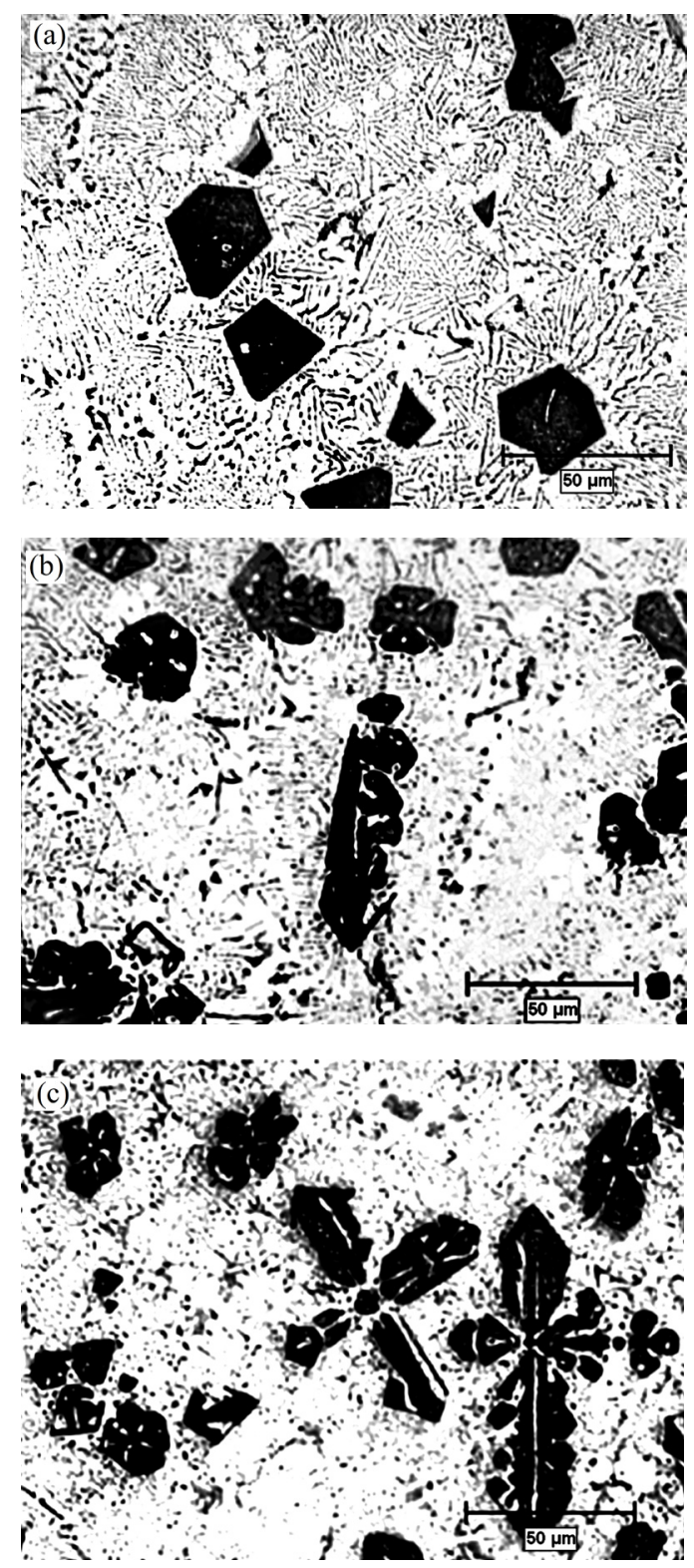

Fig. 7: Microstructure of $\mathrm{Al}-\mathrm{Mg}_{2} \mathrm{Si}$ composites with different amounts of $\mathrm{Mg}_{2} \mathrm{Si}$ : (a) $15 \mathrm{wt} . \%$, (b) $20 w t . \%$, and (c) $25 w t . \%$

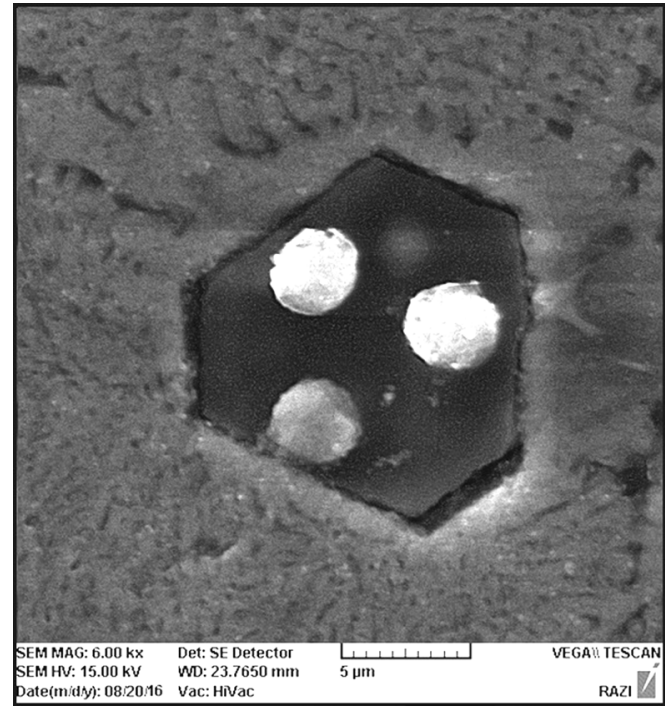

Fig. 8: Enlarged electron image of an $\mathrm{Mg}_{2} \mathrm{Si}$ primary particle

size changes from finer to coarser. It is well understood that fine particles and irregular morphologies cause lower fluidity lengths ${ }^{[17]}$. However, from the point of view that the primary $\mathrm{Mg}_{2} \mathrm{Si}$ particles are produced throughout solidification (in-situ process), the microstructural effects of the particles cannot be the origin of the resulted fluidities.

According to Fig. 1, with increasing the amount of $\mathrm{Mg}_{2} \mathrm{Si}$, the solidification interval increases, and hence the solidification mode changes from skin to pasty mode ${ }^{[34]}$. It is well documented that skin mode solidification occurs in the case of pure and eutectic metals, where in the case of alloys with solidification interval, the pasty mode happens ${ }^{[35]}$. In addition, it is well known that skin mode has the highest fluidity length. Moreover, with increasing the solidification interval, the fluidity decreases due to pastier mode ${ }^{[34,35]}$. In skin mode, the solidification starts from the mold walls, and then the solid parts grow to the center part of the channel (Fig. 9). Thus, in skin mode, when the solidification is $100 \%$ completed, the fluid flow stops ${ }^{[34,35]}$. In the case of pasty mode, equiaxed solid parts form in front of the fluid flow. In pasty mode, when the solidification is about $50 \%-60 \%$ completed, the fluid flow stops ${ }^{[17,18]}$. Therefore, according to the phase diagram and the solidification intervals, the mode of solidification for all of the composites is pasty. With increasing the amount of $\mathrm{Mg}_{2} \mathrm{Si}$, the solidification changes to be pastier, and consequently has lower fluidity.

\section{Conclusions}

(1) The ANOVA shows that the developed models can predict the fluidity of the composites, accurately.

(2) The order of effective parameters on the fluidity according to the developed models is channel thickness, superheat, mold temperature, and $\mathrm{Mg}_{2} \mathrm{Si}$ content. 


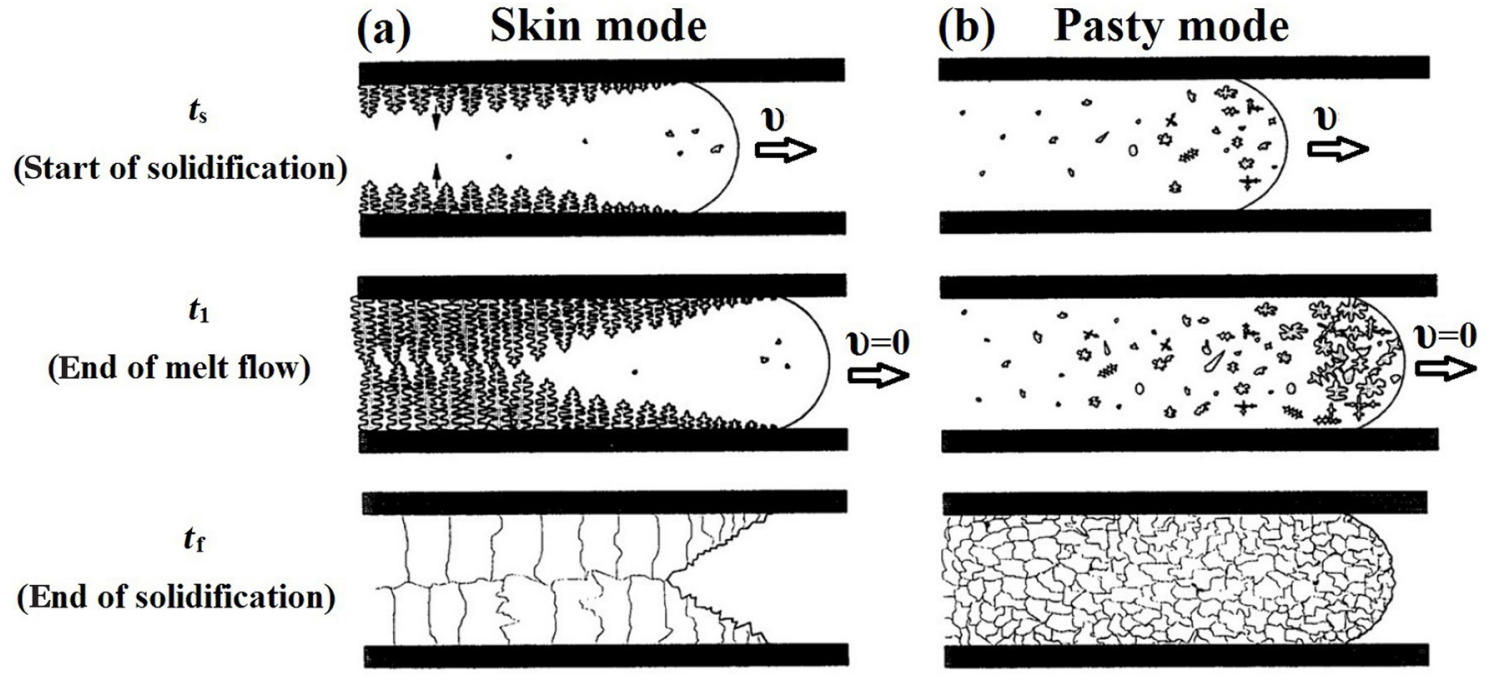

Fig. 9: Different modes of solidification: (a) skin mode, and (b) pasty mode

(3) By increasing the channel thickness (from $3 \mathrm{~mm}$ to 12 $\mathrm{mm}$ ), superheat (from $50{ }^{\circ} \mathrm{C}$ to $250{ }^{\circ} \mathrm{C}$ ), and mold temperature (from $25^{\circ} \mathrm{C}$ to $200{ }^{\circ} \mathrm{C}$ ), the fluidity length increases from $1.3 \mathrm{~cm}$ to $21 \mathrm{~cm}$.

(4) By increasing the $\mathrm{Mg}_{2} \mathrm{Si}$ content from $15 \mathrm{wt} . \%$ to $25 \mathrm{wt} . \%$, the amount and size of primary $\mathrm{Mg}_{2} \mathrm{Si}$ particles are increased, and their morphology changes from faceted to irregular and dendritic.

(5) At a higher amount of $\mathrm{Mg}_{2} \mathrm{Si}(15 \mathrm{wt} . \%$ to $25 \mathrm{wt} . \%)$, the eutectic phases become fewer and coarser.

(6) As the $\mathrm{Mg}_{2} \mathrm{Si}$ increases from $15 \mathrm{wt} . \%$ to $25 \mathrm{wt} . \%$, the fluidity of the composites decreases from $1.3 \mathrm{~cm}$ to $21 \mathrm{~cm}$.

\section{References}

[1] Fadavi Boostani A, Tahamtan S, Jiang Z Y, et al. Enhanced tensile properties of aluminium matrix composites reinforced with graphene encapsulated SiC nanoparticles. Composites Part A: Applied Science and Manufacturing, 2015, 68:155-163.

[2] Beigi Khosroshahi N, Taherzadeh Mousavian R, Azari Khosroshahi R, et al. Mechanical properties of rolled A356 based composites reinforced by $\mathrm{Cu}$-coated bimodal ceramic particles. Materials \& Design, 2015, 83: 678-688.

[3] Mohammadpour M, Khosroshahi R A, Mousavian R T, et al. A Novel Method for Incorporation of Micron-Sized SiC Particles into Molten Pure Aluminum Utilizing a Co Coating. Metall and Materi Trans B, 2015, 46(1): 12-19.

[4] Mousavian R T, Damadi S R, Khosroshahi R A, et al. A comparison study of applying metallic coating on $\mathrm{SiC}$ particles for manufacturing of cast aluminum matrix composites. Int $J$ Adv Manuf Technol, 2015, 81(1-4): 433-444.

[5] Soltani S, Azari Khosroshahi R, Taherzadeh Mousavian R, et al. Stir casting process for manufacture of Al-SiC composites. Rare Met, 2015, 36 (7): 581-590.

[6] Heidarzadeh A, Mousavian R, Khosroshahi R, et al. Empirical model to predict mass gain of cobalt electroless deposition on ceramic particles using response surface methodology. Rare Met, 2017, 36 (3): 209-219.

[7] Vatankhah Barenji R, Khojastehnezhad V M, Pourasl H H, et al. Wear properties of $\mathrm{Al}-\mathrm{Al}_{2} \mathrm{O}_{3} / \mathrm{TiB}_{2}$ surface hybrid composite layer prepared by friction stir process. Journal of Composite Materials, 2015, 34(3): 1-10.

[8] Madadi F. Study of the Microstructures and Abrasive Characteristics of Mo-Fe-C Hardfacing Alloys Fabricated by Gas Tungsten Arc Welding. Tribology Transactions, 2014, 58 (2): 225-230.

[9] Roshan M R, Mousavian Taherzadeh R, Ebrahimkhani $\mathrm{H}$, et al. Fabrication of Al-based composites reinforced with $\mathrm{Al}_{2} \mathrm{O}_{3}-\mathrm{Tib}_{2}$ ceramic composite particulates using vortex-casting method. Journal of Mining and Metallurgy B: Metallurgy, 2013, 49 (3): 299-305.

[10] Tjong S C, Ma Z Y. Microstructural and mechanical characteristics of in situ metal matrix composites. Materials Science and Engineering R: Reports, 2000, 29 (3-4): 49-113.

[11] Reddy B S B, Das K, Das S. A review on the synthesis of in situ aluminum based composites by thermal, mechanical and mechanical-thermal activation of chemical reactions. J Mater Sci, 2007, 42(22): 9366-9378.

[12] Emamy M, Nemati N, Heidarzadeh A. The influence of $\mathrm{Cu}$ rich intermetallic phases on the microstructure, hardness and tensile properties of $\mathrm{Al}-15 \% \mathrm{Mg}_{2} \mathrm{Si}$ composite. Materials Science and Engineering A, 2010, 527(12): 2998-3004.

[13] Qin Q D, Zhao Y G, Liu C, et al. Strontium modification and formation of cubic primary $\mathrm{Mg}_{2} \mathrm{Si}$ crystals in $\mathrm{Mg}_{2} \mathrm{Si} / \mathrm{Al}$ composite. Journal of Alloys and Compounds, 2008, 454(1-2): 142-146.

[14] Mousavian R T, Khosroshahi R A, Yazdani S, et al. Fabrication of aluminum matrix composites reinforced with nano- to micrometer-sized SiC particles. Materials and Design, 2016, 89: $58-70$

[15] Prukkanon W, Srisukhumbowornchai N, Limmaneevichitr C. Influence of Sc modification on the fluidity of an A356 aluminum alloy. Journal of Alloys and Compounds, 2009 , 487(1-2): 453-457.

[16] Ravi K R, Pillai R M, Amaranathan K R, et al. Fluidity of aluminum alloys and composites: A review. Journal of Alloys and Compounds, 2008, 456 (1-2): 201-210.

[17] Di Sabatino M, Arnberg L. Castability of aluminium alloys Trans Indian Inst Met., 2009, 62 (4-5): 321-325.

[18] Çolak M, Kayikci R, Dispinar D. Influence of Different Cross Sections on Fluidity Characteristics of A356. Trans Indian Inst Met., 2015, 68 (2): 275-281.

[19] Yarandi F M, Rohatgi P K, Ray S. Fluidity and microstructure 
formation during flow of $\mathrm{Al}-\mathrm{SiC}$ particle composites. J of Materi Eng and Perform, 1993, 2 (3): 359-364.

[20] Zhang Z, Chen X G, Charette A. Fluidity and microstructure of an $\mathrm{Al}-10 \% \mathrm{~B}_{4} \mathrm{C}$ composite. J Mater Sci, 2009, 44 (2): 492-501.

[21] Heidarzadeh A, Emamy M, Rahimzadeh A, et al. The Effect of Copper Addition on the Fluidity and Viscosity of an Al-Mg-Si Alloy. J Mater Eng Perform, 2014, 23 (2): 469-476.

[22] Yarandi F M, Rohatgi P K, Ray S. Fluidity and microstructure formation during flow of Al-SiC particle composites. J Mater Eng Perform, 1993, 2 (3): 359-364.

[23] Surappa M K, Rohatgi P K. Fluidity of aluminum-silicon-alumina composite. Met Trans B, 1981, 12 (2): 327-332.

[24] Kolsgaard A, Brusethaug S. Fluidity of aluminium alloy AISi7Mg-SiC particulate composite melts. Mater Sci Technol, 1994, 10(6): 545-551.

[25] Nath D, Rohatgi P K. Damping capacity, resistivity, thermal expansion and machinability of aluminium alloy-mica composites. J Mater Sci, 1981,16 (11): 3025-3032.

[26] Yarandi F M, Rohatgi P K, Ray S. Casting Characteristic of Aluminum Alloy. AFS Trans,1992, 153(96-166): 1097-1108.

[27] Barenji R V, PourasI H H, Khojastehnezhad V M. Electrical discharge machining of the AISI D6 tool steel: Prediction and modeling of the material removal rate and tool wear ratio. Precision Engineering, 2016, 45: 435-444.

[28] Aich U, Banerjee S. Modeling of EDM responses by support vector machine regression with parameters selected by particle swarm optimization. Applied Mathematical Modelling, 2014, 38 (11-12): 2800-2811.

[29] Elangovan K, Balasubramanian V, Babu S. Predicting tensile strength of friction stir welded AA6061 aluminium alloy joints by a mathematical model. Materials \& Design, 2009, 30 (1): 188193.

[30] Shanmuga Sundaram N, Murugan N. Tensile behavior of dissimilar friction stir welded joints of aluminium alloys. Materials \& Design, 2010, 31 (9): 4184-4193.

[31] Rajakumar S, Balasubramanian V. Establishing relationships between mechanical properties of aluminium alloys and optimised friction stir welding process parameters. Materials \& Design, 2012 40: 17-35.

[32] Gopalakannan S, Senthilvelan T. EDM of cast AI/SiC metal matrix nanocomposites by applying response surface method. Int J Adv Manuf Technol, 2013, 67 (1-4): 485-493.

[33] Heidarzadeh A, Khodaverdizadeh H, Mahmoudi A, et al. Tensile behavior of friction stir welded AA 6061-T4 aluminum alloy joints. Materials and Design, 2012, 37: 166-173.

[34] Ravi K R, Pillai R M, Amaranathan K R, et al. Fluidity of Aluminium Alloys and Composites: A Review. J Alloy Compd, 2008, 456 (1-2): 201-210.

[35] Flemings M C. Solidification Processing. McGraw-Hill Inc, London, 1974: 219-224. 